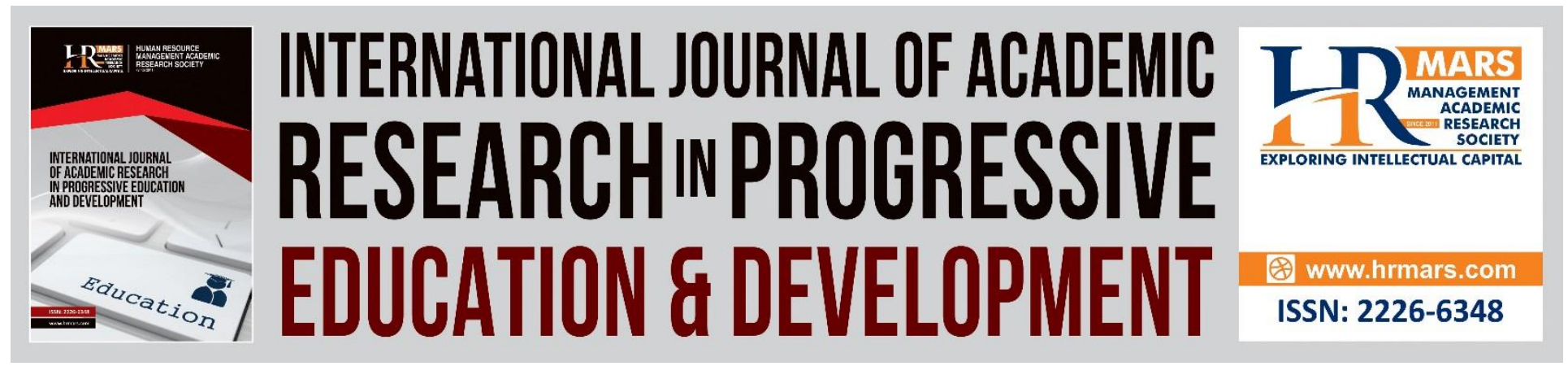

\title{
Conceptualizing Personal Knowledge Management Enabler and Personal Knowledge Management Capability
}

Norliya Ahmad Kassim, Iszurin Sha'ari, Kasmarini Baharuddin

To Link this Article: http://dx.doi.org/10.6007/IJARPED/v7-i1/3853

DOI: $10.6007 /$ IJARPED/v7-i1/3853

Received: 11 Dec 2017, Revised: 07 Jan 2018, Accepted: 26 Feb 2018

Published Online: 27 Feb 2018

In-Text Citation:

To Cite this Article:

Copyright: @ 2018 The Author(s)

Published by Human Resource Management Academic Research Society (www.hrmars.com)

This article is published under the Creative Commons Attribution (CC BY 4.0) license. Anyone may reproduce, distribute, translate and create derivative works of this article (for both commercial and non-commercial purposes), subject to full attribution to the original publication and authors. The full terms of this license may be seen

at: http://creativecommons.org/licences/by/4.0/legalcode

Vol. 7, No.1, January 2018, Pg. 24 - 37

http://hrmars.com/index.php/pages/detail/IJARPED

JOURNAL HOMEPAGE

Full Terms \& Conditions of access and use can be found at http://hrmars.com/index.php/pages/detail/publication-ethics 


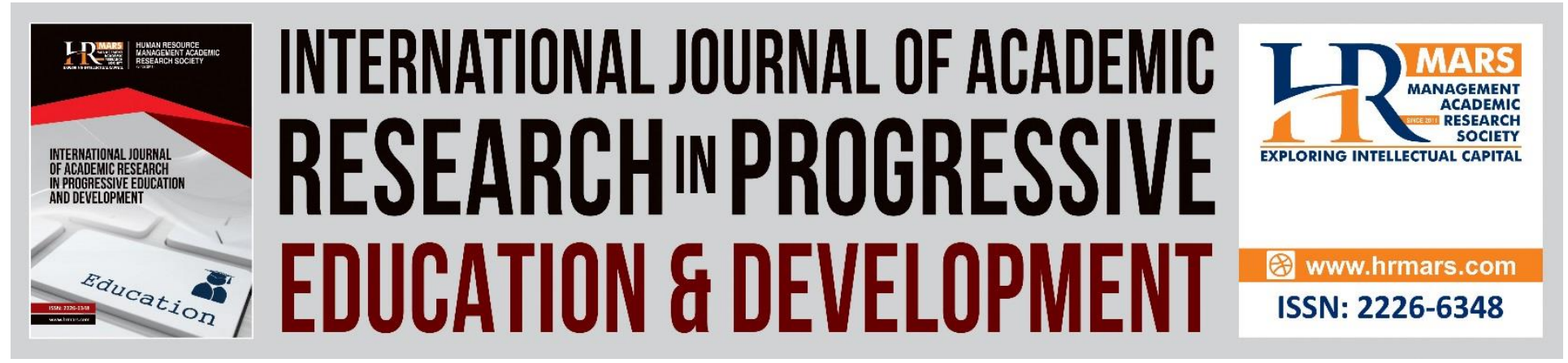

\title{
Conceptualizing Personal Knowledge Management Enabler and Personal Knowledge Management Capability
}

\author{
Norliya Ahmad Kassim \\ Faculty of Information Management, Universiti Teknologi MARA (UiTM), Selangor, MALAYSIA \\ Email: norliya@salam.uitm.edu.my
}

Iszurin Sha'ari

Faculty of Information Management, Universiti Teknologi MARA (UiTM), Selangor, MALAYSIA

Email: iszurin.phd.2017@gmail.com

\begin{abstract}
Kasmarini Baharuddin
Faculty of Information Management, Universiti Teknologi MARA (UiTM), Selangor, MALAYSIA

Email: kas@uitm.edu.my
\end{abstract}

\begin{abstract}
Personal Knowledge Management or PKM is the process and strategy in expanding personal knowledge of individuals. PKM requires individuals to organize information that they obtained from learning or knowledge acquiring activities where they transform disorganized information into systemic application information thus turning information into useful knowledge. The process requires individuals to retrieve, evaluate, organize, collaborate, analyze, present and secure knowledge in their personal knowledge bank. In short all the processes denote organization activity of knowledge retention, retrieval and utilization. The ability of individuals to perform the systemic act leads to the description of Personal Knowledge Management Capability of individuals. In this sense PKM acts and function no differently than an organization memory or KM system and the lessons acquired through combination of practical and theoretical learning by individuals need to be kept and retained in ones' personal knowledge bank for future retrieval and utilization. This requires Personal Knowledge Management of individuals to be geared in effectively. This paper reviews related literature that leads to developing a conceptual framework on Personal Knowledge Management Enabler towards Personal Knowledge Management Capability of individuals. Based on the literature review, three independent variables have been identified namely Knowledge Concept Awareness (KCA), Knowledge Retention Practice (KRP) and Knowledge Retrieval and Utilization Practice (KRUP) of which the trio represents the elements of
\end{abstract}


INTERNATIONAL JOURNAL OF ACADEMIC RESEARCH IN PROGRESSIVE EDUCATION AND

DEVELOPMENT

Vol. 7, No.1, January 2018, E-ISSN: 2226-6348 ๑ 2018 HRMARS

Personal Knowledge Management Enabler that lead to the dependent variable; Personal Knowledge Management Capability.

Keywords: Knowledge Management, Personal Knowledge Management, Personal Knowledge Management Enabler, Personal Knowledge Management Capability

\section{Introduction}

Personal Knowledge Management (PKM) or also referred as Personal Information Management (PIM) has become an interest in the study of knowledge management due to the management attributes of knowledge itself which is best accomplished by people; the movers and shakers of knowledge or the best knowledge manager (Jafari, Akhavan \& Nikookar, 2013). This understanding leads to the importance of managing personal knowledge before delving into organizational knowledge management. Jafari, Akhavan and Nikookar further iterated that the benefit of PKM is not only at individual level as the combination of PKM with organizational KM would bring about powerful management of knowledge in and within organizational components. They also highlighted that PKM is a recent knowledge management subject being studied as previous researchers and scholars focuses the study of knowledge management at organizational level rather than studying how knowledge workers organize their knowledge at individual or personal level. PKM took to being a second fiddle in knowledge management (a subset of knowledge management) as opined by Li and Li (2009).

Having understood PKM's importance and positioning, it is imperative for us to know what Personal Knowledge Management is. Again, Jafari, Akhavan and Nikookar (2013) took the best of Frand and Hixon (1999) and Avery et al. (2001)'s description of PKM, and summarized that PKM refers to the Process and Strategy of individuals in expanding personal knowledge where the individuals organize information they obtained from learning or knowledge acquiring activities as a part of their own knowledge and in doing so individuals transform loose information fragments into systemic application information; turning information into useful knowledge. Thus PKM warrants for individuals to execute the process of (1) retrieving, (2) evaluating, (3) organizing, (4) collaborating, (5) analyzing, (6) presenting, and (7) securing information in their personal knowledge bank. In short, all the processes in PKM denote the activity of knowledge retention, retrieval and utilization of individuals in managing knowledge. An understanding can also be made that in order to develop effective PKM capability, individuals must at first be in the know of knowledge concepts as this will enable individuals to identify the type of knowledge that is dealt with daily. PKM capability is also coloured with the doing or ability to carry out processes of retaining information and knowledge, retrieving it and consequently utilizing knowledge to perform as to be competent in task or work implementation.

Based on the above descriptions by researchers it can be said that PKM works on the principles, processes and mechanics that information must be "Retained", "Retrieved" and "Utilized". As to understand how knowledge retention and knowledge retrieval goes about in the process, individuals need to first ensure that they have the basic understanding of what "Knowledge" and its components are and the characteristic or the form it takes. The absence of such would impair a person conceptual understanding in building and making their PKM works to their needs. Therefore in describing PKM in general and also in investigating issue in this study, one has to first look at grasping the following understanding of;

- Knowledge (Data, Information and Knowledge) 


\section{DEVELOPMENT}

Vol. 7, No.1, January 2018, E-ISSN: 2226-6348 @ 2018 HRMARS

- Knowledge Format (Tacit and Explicit)

- Knowledge Creation (Socialization, Externalization, Combination and Internalization)

- Knowledge Retention (Personalization and Codification)

- Knowledge Retrieval and Utilization

- Personal Knowledge Management

The imperative understanding as highlighted will be the explored in this literature review journey. In this view, the objective of this paper is to review literature that leads to the conceptualization of the following component of Personal Knowledge Management (PKM) as follows:

1) Personal Knowledge Management Enabler

- Knowledge Concept Awareness (Data, Information, Knowledge, Tacit, Explicit, Creation)

- Knowledge Retention Practice (Personalization and Codification)

- Knowledge Retrieval \& Utilization Practice and

2) Personal Knowledge Management Capability

The paper concludes by presenting a conceptual framework on Personal Knowledge Management Enabler towards Personal Knowledge Management Capability of individuals. This framework would be beneficial in the study of Personal Management Enabler and Capability and the information derived could be used by institutions to develop learning strategy guidance or learning management module in developing the ability to capture, retain and retrieve lessons learnt for utilization; in certifications or work implementations.

\section{What is Personal Knowledge Management (PKM) Enabler?}

Personal Knowledge Management (PKM) enabler consists of elements, factors or variables that interact with each other in enabling PKM to be geared effectively by individuals. In respect of this paper that is based on findings and opinions by researchers mentioned in the introductory PKM Enabler can be grouped as knowledge concept awareness (KCA), knowledge retention practice (KRP) and knowledge retrieval-utilization practice (KRUP). The dynamic interaction of the element would in turn influence and affect capability of individuals to carry out personal knowledge management activity diligently.

\section{Knowledge Concepts Awareness (KCA)}

Knowledge Concepts Awareness (KCA) is about the understanding of what data, information and knowledge is and how they exist as tacit and explicit knowledge. An understanding on how data, information and knowledge interact and transform to be useful knowledge is imperative to conclude sound awareness of knowledge concepts. This is also the highlights of Nonaka and Takeuchi (1995) in their famous SECI model.

\section{Data}

Freeze and Kulkarni (2007) defined data as raw numbers and facts that are arranged hierarchically and when aggregated if forms information as to provide knowledge. The simple description in a way shows the relationship between data, information and 
Vol. 7, No.1, January 2018, E-ISSN: 2226-6348 @ 2018 HRMARS

knowledge. Data may also include facts or figures that are summarized from surveys, experiments and operations.

\section{Information}

In terms of its definition and technicalities that is comprehensive, Busch (2008) explained that information is not similar to data but the concept of information likened the concept of knowledge and competence. In order to produce information, an interpretation needs to be made on our experience and what we know to be turned into the explicit, however information will be in bits and pieces. It is what is explicitly symbolized on paper or on screen. It needs to be related and connected to individual's practice, personally and intrinsically to make sense of it to the next level, becoming knowledge and competence.

\section{Knowledge}

Freeze and Kulkarni (2007) pictured knowledge in its more specialized form as "Expertise Knowledge" which is a "highly tacit/implicit, specific to a domain, originated via experience, formal education and collaboration." This is the knowledge that is strategically developed in a person or organization to command act of works or be used almost entirely in day to day execution of works. Busch (2008) also pointed out that knowledge are sticky, the stickiness is due to the way knowledge conform and adhere to particular individuals or context therefore knowledge is not that easy to be transferred or transform. However codified knowledge (explicit) is less sticky than tacit knowledge as it has a form whilst tacit form is still in the mind of people. Knowledge therefore is seen as a mix-blend of various elements that are at times codified and at times tacit.

\section{Knowledge Format}

Tacit and explicit knowledge are like the two sides of a coin; neither one is similar but both hold equal importance as to enable a coin to be a coin. In its simplicity Polanyi (1958) made the world of information management understand that knowledge existed in the two forms mentioned. In short tacit knowledge are knowledge that resides in a person, i.e. thoughts, ideas, expertise, skills, experience, feelings and the likes while explicit knowledge are tacit knowledge that has been codified for it to be seen clearly in documents by others, the codification is also referred to as knowledge capture.

\section{Tacit Knowledge}

Martin and Meyer (2012) explained that tacit knowledge are knowledge that may not be "verbalized" or "documented" easily as it is embedded in people's behaviour through "cognitive" and "knowledge" constructs. Tacit knowledge resides in people; in individuals and groups of individuals that member organization or such; they are the carriers of knowledge (Martins \& Martins, 2011). It manifested itself into people's cognitive sets through observation, learning and studying the surroundings, and both tacit and explicit knowledge can be constructed or created when it is shared, transferred and applied in the environment people are in. Martin and Meyer (2012) elaborated further on an opinion by DeLong (2004) that in today's world, the carriers of knowledge, interacts in their working environment and created substantial knowledge that is experiential in nature, such knowledge are tacit and only part of this knowledge is able to be shared and documented compared to knowledge that are explicit. Campos and Sa'nchez (2003) 
Vol. 7, No.1, January 2018, E-ISSN: 2226-6348 @ 2018 HRMARS

further iterated that it is highly impossible to turn all tacit knowledge into explicit form and about 50 to 90 percent of organizational knowledge is preserved in peoples mind. Tacit knowledge may be made explicit to an extent and there are tacit knowledge that is quite impossible to be transformed. Li and Goa (2003) labelled tacit knowledge that is not transformable as "tacit knowing" that is elusive and subjective to individuals, and cannot be articulated using words. This is in line with what was shared by Polanyi (1958) in the early years that not all knowledge can be codified.

\section{Explicit Knowledge}

In describing explicit knowledge, Freeze and Kulkarni (2007) explained knowledge documents as explicit knowledge and itirated that explicit knowledge documents must be represented in diverse type of documentation. It can be in a structured or unstructured format. Traditionally structured format is in "text based" form such as publications, reports, articles etc while the unstructured format is "non-text based" such as presentations, pictures, diagrams, drawings, audio clips, video clips, on-line documents etc. In order to understand Explicit Knowledge, one has to look from the angle of both tacit and explicit knowledge. In this respect, no better explanation can be given without going through the lens of Nonaka and Takeuchi (1995) in their SECI model. Nonaka and Takeuchi modelled knowledge transformation in four forms of "Socialization-Tacit to Tacit", "Externalization-Tacit to Explicit", "Combination-Explicit to Explicit" and "Internalization-Explicit to Tacit" that explains the dynamic knowledge transformation between the tacit and explicit.

Having understood what tacit and explicit knowledge are, we will arrive at a juncture and be asking which are more important than the other? Is it tacit knowledge or explicit knowledge? It is not debatable though as it would be asking oneself which came first, the chicken or the egg? Both are equally important to form the world of knowledge, one cannot do without the other or we would find ourselves back in the stone age, having the orals only as the means of communicating with each other but eventually we will be seeking ways to manifest our verbal into some kind of recording, as to leave our marks in time; that's when cave drawing became popular. In short the one support the other as a complete means of living and going about businesses and managing things in life.

However, looking at the context of tacit knowledge over time, Noe, Gerhart and Wright (2003) in Martin and Meyer (2012) remarked that tacit knowledge is highly critical in organizations as tacit knowledge in organizations is based on knowledge and skills that builds up over a period of time via individual employees experiences. That could be applicable in certain instances or maybe in the past. The $21^{\text {st }}$ century saw to that many organizational initiatives were geared to document the tacit and digitalized what has been captured as well (Megill, 1997). This is an indication that the importance of tacit and explicit equals and complimented each other. An organization might resort back to the tacit if the explicit are lost or became unavailable i.e. when files or documents goes missing or lost in a hazard, organization immediately acts to preserve lost content by interviewing related employees as to obtain back information that resides in documents in the file. The oral records would then again be turn to explicit documents or reports and a new file is created, preserving the lost information. However Martin and Meyer (2012) 


\section{DEVELOPMENT}

Vol. 7, No.1, January 2018, E-ISSN: 2226-6348 @ 2018 HRMARS

stressed that Noe et al. (2003) do have the strength of argument as, if an explicit document is lost, one would resort to seek the next best thing which is the origin of the explicit information, that is, the people holding the knowledge. Important tacit knowledge could be about organization affairs, businesses, strategies, products, services, processes etc.

\section{Knowledge Creation}

Understanding of knowledge creation is important in Personal Knowledge Management (PKM) as we need to understand how information is transformed between their tacit and explicit format as to be retained in PKM as the way it is best required for effective retrieval. In this respect one would not be able to ignore the universals of Nonaka and Takeuchi (1995)'s knowledge creation model. The model core mechanism to be understood is that for knowledge to be transferred between formats or to PKM, the knowledge has to be made fluid into the form of information for it to be moved and retained again. Nonaka based part of his model and theory on the work of Polanyi (1958) that carved the principle knowledge explicit and tacit knowledge are inseparable from each other and are connected. Nonaka provided exemplary of tacit knowledge being extracted to be explicit and then reinitialize as tacit. This process is ongoing all the time to which knowledge retention is made at any stage of the knowledge creation cycle.

Knowledge creation may take four modes and each mode of conversion or transformation constitutes one means of knowledge creation or transfer. The gist of understanding on the four modes are: (1) Socialization - an organizational process where tacit knowledge of individuals is transferred in tacit form to others that they interact with and vice versa, it is primarily a process between individuals, (2) Externalization - refers to the transformation of tacit knowledge into explicit knowledge when the knowledge is turned into an explicit form. One instance is the articulation of one's own tacit knowledge into ideas or images in words, metaphors, analogies, theories, concepts, models, and the likes, (3) Combination - refers to the conversion of explicit knowledge to some new form of explicit knowledge as well, by combining different bodies of explicit knowledge, new categories or form of explicit knowledge are produced. This is the area where information technology is most helpful, because explicit knowledge can be conveyed in documents, email, data bases, as well as through meetings and briefings, and (4) Internalization - takes its place when learning occurs, people are taught and learned to perform specific task. It is the process of understanding and absorbing explicit knowledge in to tacit knowledge held by the individual.

\section{Knowledge Retention Practices (KRP)}

The Reader's Digest Association (1993) described "retention' as the act of "retaining" and in entailing retaining knowledge, it worded the description as "keeping possession of knowledge, not to lose knowledge, continuing to have knowledge and practicing or recognizing knowledge". Based on the dictionary description which is quite comprehensive, we can conclude that knowledge retention is an action that we initiate to keep in possession as not to lose and continuing to have, practice and recognize knowledge. On the other hand and from the perspective of knowledge management and organizational behaviour, Martin and Meyer (2012) 


\section{INTERNATIONAL JOURNAL OF ACADEMIC RESEARCH IN PROGRESSIVE EDUCATION AND}

\section{DEVELOPMENT}

Vol. 7, No.1, January 2018, E-ISSN: 2226-6348 @ 2018 HRMARS

defined knowledge retention as maintaining as not to lose the existing knowledge in peoples mind which is tacit and not easily documented, and also the "knowing" that is important to the functions of organization. "Knowing" in this context means the experiential action shown in behaviours.

DeLong (2004) in Martin and Meyer (2012) quoted, "Knowledge retention is effectively the act of building organizational memory." The statement is very fitting to the course of knowledge retention and very much beginning with the end in mind (Covey, 1997). Not only is knowledge retention aimed at having memory incorporated into organizations at the end of the day, the same goes for other knowledge management intervention as well. However knowledge retention is the core and main principle of developing a memory function either in organizations or in individuals. Martin and Meyer (2012) cited Du Plessis (2003) to add that the implications of not retaining knowledge is that, organization or people will not have any references in learning from past experiences thus resulting in them having to reinvent the wheel repeatedly. In breaking on thoughts on how to retain knowledge to be referred, Freeze and Kulkarni (2007) explained that knowledge obtained during and after executing tasks, works, projects or in any other specific situation are known as "best practices", "best known methods" and "internal benchmarking" and such knowledge needs technology that enables codification taxonomy to document, apply and reuse it later. What is being kept and referred thus become lessons learned therefore when we retain knowledge, we retain all the valuable lessons in things done at individual or organizational level.

\section{Personalization}

As most knowledge of individuals and organizations are in the tacit as explained above, the statement on knowledge retention of the tacit by Martin and Meyer (2012); "..... maintaining as not to lose the existing knowledge in people's mind which is tacit and not easily documented, and also the 'knowing' that is important to the functions of organization, captures the essence of personalization. In personalization, knowledge that is of tacit nature is transferred or transform from people to people". Personalization involves the human element touch in enabling knowledge to be moved or enriched. Communication and its manner including the processes of transferring tacit knowledge are the focus in personalization. Personalization is the means to move information and knowledge that are not able to be codified. Some examples are teaching, sharing knowledge, discussions, presentations etc. Hansen, Nohria and Tierney (1999) added the final touch of simplicity in understanding and summarized personalization as personal interactions that must be practiced in transferring knowledge or transforming it, while the external to it such as information technology are just tools to assist in the communication between individuals or people.

\section{Codification}

The intention or purpose is to turn organizational knowledge into a form so as to enable people to access it. Literally the term codification means knowledge is to be coded as to organize it, making it explicit and easy to understand (Davenport \& Prusak, 2000). Hansen et al. (1999) shared that in codifying information and knowledge, "knowledge object" must be created to link and reuse codified knowledge as to provide ease for users to access it without having the needs to contact people that developed the objects. The retrieval or reuse of codified knowledge must 
DEVELOPMENT

Vol. 7, No.1, January 2018, E-ISSN: 2226-6348 ๑ 2018 HRMARS

also include processes such as cataloguing, storage and retrieval methods and the processes must be created to enable both structured and unstructured format of knowledge. Freeze and Kulkarni (2007) provided more examples of codified knowledge by citing McDermott (1999) elaboration that codified knowledge may take its form in maps, statistics, procedurals, analysis and others.

\section{Knowledge Retrieval and Utilization Practice (KRUP)}

Knowledge Retrieval is a process where information and knowledge is "reconstituted" and "reconstructed" as to be made "available" for it to be referred and used (Gammelgaard \& Ritter, 2005). A simple example of retrieving and utilization knowledge is reading a document or pages from a book and accessing what is encoded in the writings of information, symbols, pictures, map, flows etc. The focus or issue will be on how is the obtained knowledge, understood by individuals? Therefore retrieval involved searching and decoding activity where searching for information is done based on the intention of it and decoding of information is the "reconstruction" of information to fulfil user's needs (Krippendorff, 1975). In view of retrieval and utilization of information, the task has been made convenient by information technology. However Gammelgaard and Ritter (2005) highlighted that there might be problems or difficulties between the two in terms of "context specificity" (context of information by creator) and "absorptive capacity" (context of information decoded by retriever). The issues highlighted in the classics will not be of great problem or hindrance in creating an effective personal memory (PM) or personal information management (PIM) because PIM's creator and retriever of information are similar individuals. The creation of individual PIM's is to personally manage information and knowledge from the surrounding of the individual in overcoming memory capability issues of people or human being. However attention to these issues need to be drawn and not be taken for granted as what is created through knowledge retention by similar individuals, and if not done properly will make retrieval fruitless.

\section{Personal Knowledge Management (PKM)}

"What one does, one remembers". The common statement that becomes life and learning principles since long ago is very much true but considering the wealth of knowledge that exist in today's electronic information age, it has its limiting extension. The context that is portrayed is about memory; the greatest tool that people possessed. Memory is a critical component of our cognitive system as it serves as the foundation in interpreting and constructing a scheme or mechanics for organizing knowledge, and it foreground mental models that represent one's view of the world (Volkel \& Haller, 2009; Senge, 1997). Mrchev (1990) describes that memory controlling system belongs to both "animate" or "inanimate objects", therefore memory can be biologically owned by humans as well as existing in an artificial built like the computer.

Koskinen and Aramo-Immonen (2008) elaboration of personal memory may be taken to describe the technicalities for the above concept of memory. According to their study, personal memory can be developed by using memory aids "device" or "strategies" of which they cited Harris (1980)'s classification of memory aids. The first is individuals internal memory of mental rehearsing and alphabetic searching to strike remembrance. The second has got to do with using physical or tangible aids like making a list or notes of things to be remembered where it can be taken or stored anywhere to be used and referred to. In this respect, the researchers are actually relating the concept of a system in managing information accumulated by individuals, of which 
DEVELOPMENT

Vol. 7, No.1, January 2018, E-ISSN: 2226-6348 @ 2018 HRMARS

we can refer to as personal information system (PIM). Although they generalized the second personal information management as using personal notes, it can be understood that nowadays there are many avenue of making notes with the aid of IT technology and personal system available in the market such as I-Pads, desknotes, portable disks, cloud system and others.

In relations to the first memory aid mentioned by Koskinen and Aramo-Immonen (2008); human memory, of which Volkel and Haller (2009) quoted the classics of Miller (1956) that in performing work or activity that is natured to knowledge i.e. executing technical works or learning, people will be curbed with limitations of the human mind. The limitations are "longterm memory recall"; people needs to retain information and knowledge on long duration as the information or knowledge will be retrieved throughout time, and "short term capacity"; people have limited memory capacity that can only handle about seven matters at a time. These two shortcomings work against each other, making knowledge retention and retrieval not an easy task for the mind to handle. Volkel and Haller (2009) also enriched the classic 1956 scientific findings by providing suggestion on solutions that would help people alleviate issues of short memory capacity such as using external knowledge representations, i.e. taking short meaningful notes, diagram drawing or mind mapping that in a way pictured larger set of information items and thus enables maximum retrieval of information as when required. This act of putting a solution to a memory issue can be regarded as managing personal information or knowledge.

\section{Personal Knowledge Management Capability (PKMC)}

The ability of individuals to perform the systemic act leads to the description of Personal Knowledge Management Capability of individuals. Personal Knowledge Management (PKM) assists individuals or group of individuals to manage all sorts of information and knowledge effectively. It requires individual to externalize the way they manage what they have to remember and effectively keep such information in their memory for future retrieval and usage. Individual method of riding external solution or tools might differ from each other and may not be standardized as PKM conceptualize on how and what one sees fit in managing their information and knowledge, individually. In short PKM is the initiative and capability of managing information belonging to individual that is obtained via processes that was mentioned by Avery et al. (2001); (1) retrieving, (2) evaluating, (3) organizing, (4) collaborating, (5) analyzing, (6) presenting, and (7) securing information in their personal knowledge bank.

\section{Conceptual Framework}

The review of literature has enabled a conceptual framework to be developed as illustrated in Figure 1. The literature helps to form an arrangement of Independent Variables (IVs) that needs to be factored as the Enabler for PKM Capability to be developed. There are three Independent Variables (IV) of which the first is "Knowledge Concepts Awareness (KCA)" that consists individuals' comprehension aspects of Data / Information / Knowledge, Tacit and Explicit Knowledge, and Knowledge Creation. The second Independent Variables (IV) is "Knowledge Retention Practice (KRP)" that factored the understanding on how information and knowledge undergo personalization and codification process in enabling knowledge retention and the third Independent Variable (IV) is "Knowledge Retrieval \& Utilization Practice (KRUP)" that spells out the ability of retrieving and utilizing knowledge to be used for specific purposes. 


\section{DEVELOPMENT}

Vol. 7, No.1, January 2018, E-ISSN: 2226-6348 @ 2018 HRMARS

The Dependent Variable (DV) that is affected and influenced by the IVs is Personal Knowledge Management (PKM) Capability; a state of being that described the attainment or achievement of individuals in comprehending PKM, effectively or not. This may be seen in the capability of individuals in obtaining or securing, evaluating, analyzing, collaborating, organizing or retaining and presenting information and knowledge.

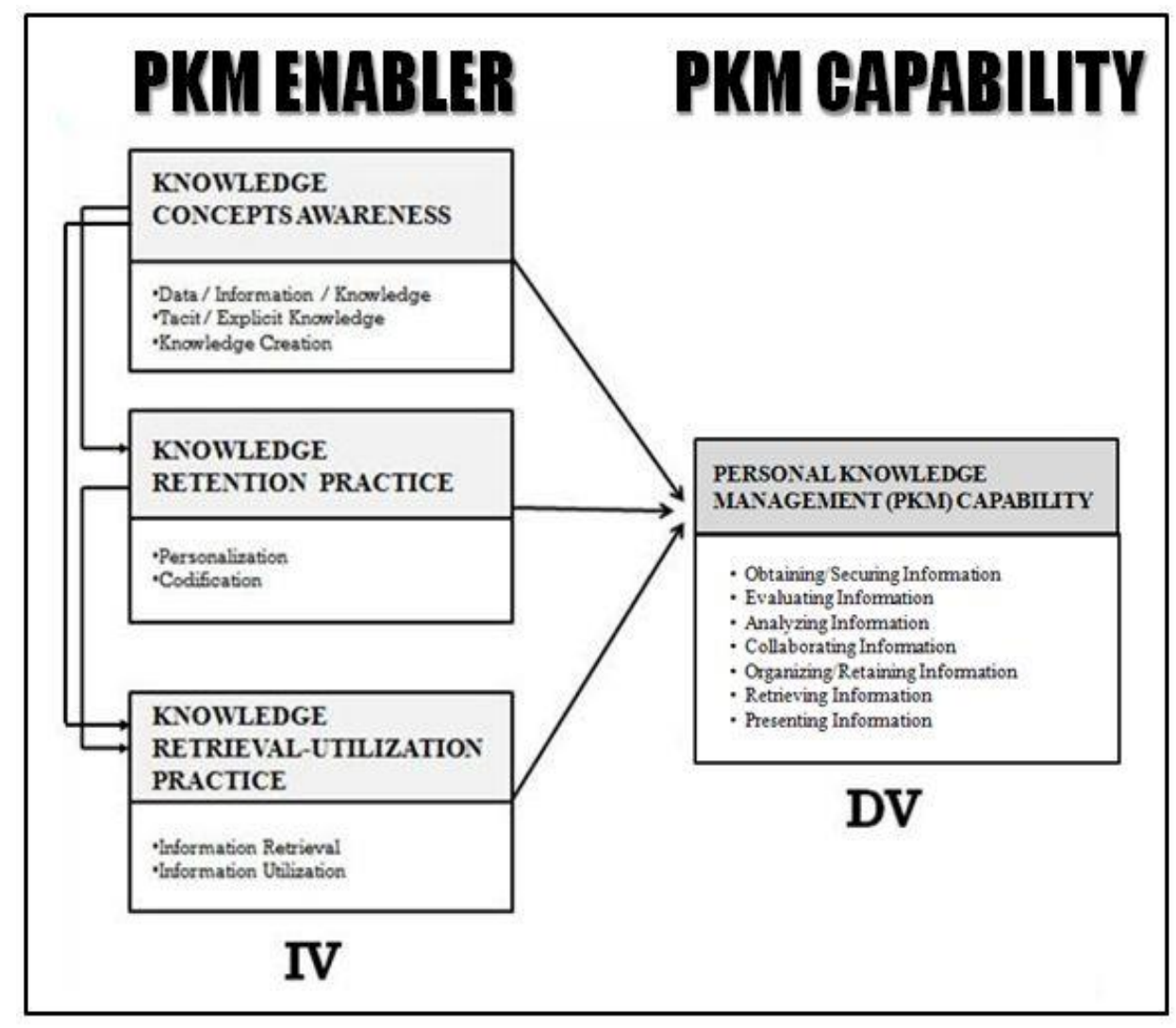

Figure 1: Conceptual Framework on Personal Knowledge Management Enabler (PKME) towards Personal Knowledge Management Capability

\section{Conclusion}

The review of past literature has led to the development of a conceptual framework that identified Knowledge Concept Awareness, Knowledge Retention Practice and Knowledge Retrieval-Utilization Practice as PKM Enabler dimensions that influence the state of being of Personal Knowledge Management (PKM Capability). Both the Enabler and Capability variables are represented by processes, actions or the conceptual knowledge that makes each variable visible, functioning, describable and measurable. In this study the Independent Variable dimension is known as the "Personal Knowledge Management (PKM) Enablers" while the Dependent Variable dimension is the "Personal Knowledge Management (PKM) Capability".

Based on the discussion on research variables that has been elaborated in the previous section and in relation to the developed Conceptual Framework, this research opined an assumption that in developing or ensuring Personal Knowledge Management (PKM) Capability of individuals in an 


\section{INTERNATIONAL JOURNAL OF ACADEMIC RESEARCH IN PROGRESSIVE EDUCATION AND}

\section{DEVELOPMENT}

Vol. 7, No.1, January 2018, E-ISSN: 2226-6348 @ 2018 HRMARS

institution; three dimensions of concern or enablers must be worked upon. The individuals' comprehension and ability to grasps (1) Knowledge Concepts Awareness or basic understanding of data, knowledge and information definition, meaning, structure and how it interacts with each other must be strongly ingrained into their cognitive comprehension. The understanding is very much principle natured, is compulsory and imperative for individuals to be able in managing knowledge retention, retrieval and utilization of the knowledge and education they received throughout their training, (2) Knowledge Retention Practice understanding is also mandatory, in order "to do", one must understand how it needs to be done. In this area or factor, ones need to be competent or in the know of how information or knowledge is transform as to be preserved either in their memory or in PKM. Information transformation basic concepts and mechanism of "personalization" (verbal transfer) and "codification" (example; writing notes in paper based platform to digital application or database) must be exposed to them as this is the element that also build a PKM. The final factor, (3) Knowledge Retrieval-Utilization Practice ability must also be common sense to the individuals as knowledge retention alone does not ensure knowledge can be used, ones need to be able to perform retrieval and utilization process systematically and effectively. With the three factors in place and working in tandem effectively as the PKM Enabler, a PKM Capability of individuals will by itself be built and developed. That is the ideal in the making of an effective Personal Knowledge Management system.

\section{Corresponding Author}

Kasmarini Baharuddin, Faculty of Information Management, Universiti Teknologi MARA (UiTM), Selangor, MALAYSIA

Email: kas@uitm.edu.my

\section{References}

Avery, S., Brooks, R., Brown, J., Dorsey, P., \& O’Conner, M. (2001). Personal knowledge management: Framework for integration and partnerships. Paper presented at 35th Annual Conference of the Association of Small Computer Users in Education (ASCUE), Myrtle Beach, SC, 11-14 June.

Busch, P. (2008). Tacit knowledge in organizational learning. Hershey, PA: IGI Pub.

Campos, E. B., \& Sa 'nchez, M. P. S. (2003). Knowledge management in the emerging strategic business process: Information complexity and imagination. Journal of Knowledge Management, 7(2), 5-17.

Covey, S. R. (1997). The 7 habits of highly effective people: Taught by the author. Provo, UT: Franklin Covey.

Davenport, T. H., \& Prusak, L. (2000). Working knowledge-how organizations manage what they Know. Boston, Massachusetts: Harvard Business School Press.

DeLong, D. W. (2004). Lost knowledge: Confronting the threat of an aging workforce. New York: Oxford University Press. 
Du Plessis, F. (2003). New era organisations: From task-driven to customer-driven and worldclass. In Moerdyk, A. \& Van Aardt, C. (Eds), Organisational development: New methods and models for Southern Africa. Glosderry: New Africa Books, 91-109.

Frand, J., \& Hixon, C. (1999). Personal knowledge management: Who, what, why, when, where, how? Working paper. Available at http://www.anderson.ucla.edu/jason.frand/researcher/speeches/PKM.htm

Freeze, R. D., \& Kulkarni, U. (2007). Knowledge management capability: Defining knowledge assets. Journal of Knowledge Management, 11(6), 94-109.

Gammelgaard, J., \& Ritter, T. (2005). The knowledge retrieval matrix: Codification and personification as separate strategies. Journal of Knowledge Management, 9(4), 133-143.

Hansen, M. T., Nohria, N., \& Tierney, T. (1999). What's your strategy for managing knowledge? Harvard Business Review, 77(2), 106-16

Harris, J. E. (1980). Memory aids people use: Two interview studies. Memory \& Cognition, 8, 3138.

Jafari, M., Akhavan, P., \& Nikookar, M. (2013). Personal knowledge management and organization's competency: A service organization case study. Education, Business and Society: Contemporary Middle Eastern Issues, 6(3/4), 181-194.

Koskinen, K. U., \& Aramo-Immonen, H. (2008). Remembering with the help of personal notes in a project work context. International Journal of Managing Projects in Business, 1(2), 193205.

Krippendorff, K. (1975). Some principles of information storage and retrieval in society. General Systems, 20, 15-35.

Li, M., \& Goa, F. (2003). Why Nonaka highlights tacit knowledge: A critical review. Journal of Knowledge Management, 7(4), 6-14.

Li, G., \& Li, Y. (2009). A study on blog based personal knowledge management. Second International Workshop on Knowledge Discovery and Data Mining, 248-251.

Martins, E. C., \& Martins, N. (2011). The role of organisational factors in combating tacit knowledge loss in organisations. South African Business Review, 15(1), 49-69.

Martins, E. C., \& Meyer, H. W. J. (2012). Organizational and behavioral factors that influence knowledge retention. Journal of Knowledge Management, 16(1), 77-96. 
INTERNATIONAL JOURNAL OF ACADEMIC RESEARCH IN PROGRESSIVE EDUCATION AND

DEVELOPMENT

Vol. 7, No.1, January 2018, E-ISSN: 2226-6348 @ 2018 HRMARS

McDermott, R. (1999). Why information technology inspired but cannot deliver knowledge management. California Management Review, 41(4), 103.

Megill, K. A. (1997). Corporate memory: Information Management in the electronic age. West Sussex, United Kingdom: Bowker-Saur.

Miller, G. A. (1956). The magical number seven, plus or minus two: Some limits on our capacity for processing information. The Psychological Review, 63, 81-97.

Mrchev, S. J. (1990). Decision-making systems in human memory modelling. Kybernetes, 19(5), 29-43.

Noe, R., Hollenbeck, J., Gerhart, B., \& Wright, P. (2003). Human resource management: Gaining a competitive advantage (4th ed.). Boston: McGraw Hill.

Nonaka, I. \& Takeuchi, H. (1995). The knowledge-creating company: How Japanese companies create the dynamics of innovation. New York: Oxford University Press.

Polanyi, M. (1958). Personal knowledge: Toward a post-critical philosophy. New York: Harper Torchbooks.

Reader's Digest Association (1993). Reader's Digest Oxford complete wordfinder. London: The Reader's Digest Association.

Senge, Peter, M. (1997). The fifth discipline: The art and practice of the Learning Organization. New York, NY: Currency Doubleday.

Volkel, M., \& Haller, H. (2009). Conceptual data structures for personal knowledge management. Online Information Review, 33(2), 298-315. 